\title{
Identification of Hydraulic Parameters of Wadi El Natrun Pliocene Aquifer Using Artificial Neural Network
}

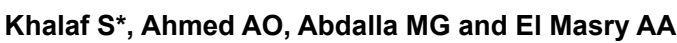

Irrigation and Hydraulics Department, Faculty of Engineering, El-Mansoura University, Egypt

\begin{abstract}
Many techniques, approaches and tools were used in this Research to achieve the Methodology. Using artificial neural network to simultaneous hydraulic parameters is one of these techniques. Transmissivity and storativity consider the most important parameter in each aquifer due to the reality of their effect on the aquifer properties. In this research, it is assumed that the transmissivity $(T)$ and the storativity $(S)$, represented by coordinates $(X),(Y)$, hydraulic head $(H)$, and observation times $(t)$. These variables were chosen depending on the literature review. In the present study, the hydraulic head values at each cell $(\mathrm{H})$ and the location of the cells $(x, y)$ are considered as input parameters for finding the unknown parameters. The transmissivity $(\mathrm{T})$ and storativity values $(\mathrm{S})$ at cells are assumed and used in the finite difference method (Forward model) in order to find the value of hydraulic head at that cell. The hydraulic head values were used in the artificial neural networks (Inverse model) to estimate transmissivity $(\mathrm{T})$ and storativity values (S) for Wadi El Natrun Depression. The study is based on coupling of forward model and inverse model. In general, the parameter estimation process consists of identifying a model that would reverse a complex forward relation.
\end{abstract}

Keywords: Parameter identification; Simultaneous; Inverse model; Neural networks; Groundwater flow; Forward model; Wadi El-Natrun

\section{Introduction}

Soft computing techniques analogous to biological nervous system are called as artificial neural networks (ANNs). The reason for wider acceptability of this technique can be attributed to its capability to develop computing tools, which may partially capture amazingly faster and complicated information-processing ability of the brain. Groundwater is an important source of water for drinking, irrigation, and industrial uses. It is also a major source for domestic water requirement. Ground water hydrology examines problems like prediction of groundwater head, distribution of transmissivity, storativity specific yield and estimation of parameters. Involved processes are nonlinear, complex, multivariate with variables having spatial and temporal variability. These are expressed by complex partial differential equations, which are normally solved with considerable approximations using complex numerical models. Precise conceptualization is nearly impossible for groundwater problems as physics of the system cannot be fully understood from the surface. ANNs can be used in groundwater hydrology since they do not require governing equations and their concomitant assumptions.

Strength of ANNs lies in mapping non-linear system data, which are capable of extracting the relation between the input and output of a process without adequate knowledge of the underlying principles. As the computational burden is primarily managed by replacing the numerical model with a surrogate simulator artificial neural network the technique of $\mathrm{ANN}$ is quite appropriate for groundwater problems.

Estimation of aquifer parameters demands large time, financial and manpower resources which are always scarce [1]. Therefore, the efforts are on increase to assess these by non-field methods using the technique of ANNs. The determination of aquifer parameters (also termed as inverse problem) has always been a challenge because of its ill-posedness [2-7]. Inversion of the trained feed forward neural network is done to estimate the transmissivity field for synthetic problem [5]. Most of the papers used synthetic or published data to assess parameters in confined aquifer [4-6,8] for the reason of nonavailability of sufficient number of patterns. Model sensitivity in terms of number of nodes in hidden layers is carried out by Shigdi et al. [5] using correlation coefficient, Y-intercept, and slope. An approach with a combination of ANNs and type curves based on Papadopoulos and Cooper analytical solution was used by Balkhair [4] whereas ANN and This solution coupling was performed by Lin GF et al. [9]. It was found that Levenberg-Marquardt achieves faster convergence than backpropagation algorithm [7]. To solve the problem of range of aquifer parameters to be used for training [4] carried out training in macro and micro scales. Macro scale is used for very wide and very narrow range whereas micro scale is for middle range of parameters. Lohani et al. [10] presents an efficient and stable artificial neural network (ANN) model for predicting groundwater level in south-east Punjab, India. Lohani et al. [11] used neural network configuration for predicting groundwater level in Amritsar and Gurdaspur districts of Punjab, India is identified. For predicting the model efficiency and accuracy, different types of network architectures and training algorithms are investigated and compared.

The determination of aquifer parameters (also termed as inverse problem) has always been a challenge because of its ill-posedness $[2-7,12,13]$. ANNs is solving many complex real world-predicting problems. ANNs have been applied to predicting groundwater levels $[14,15]$, precipitation and runoff modeling, and aquifer parameter estimations [3,5,16-19].

*Corresponding author: Dr. Khalaf S, Irrigation and Hydraulics Department, Faculty of Engineering, El-Mansoura University, Egypt, Tel: +20 50 2383781; E-mail: samykhalaf2005@yahoo.com

Received February 09, 2017; Accepted February 17, 2017; Published February 24, 2017

Citation: Khalaf S, Ahmed AO, Abdalla MG, El Masry AA (2017) Identification of Hydraulic Parameters of Wadi El Natrun Pliocene Aquifer Using Artificial Neural Network. Hydrol Current Res 8: 267. doi: 10.4172/2157-7587.1000267

Copyright: $\odot 2017$ Khalaf S, et al. This is an open-access article distributed under the terms of the Creative Commons Attribution License, which permits unrestricted use, distribution, and reproduction in any medium, provided the original author and source are credited. 
The main objectives of this study may be summarized as follows:

(1) to develop an ANN model for solving the groundwater inverse problem by providing an ANN model to solve complex nonlinear relationships.

(2) to test the performance of the proposed ANN model.

(3) to simultaneously determine the transmissivity and storativity field of an aquifer by using limited observed head values.

\section{Study area (Wadi El Natrun)}

The study area lies at El Behera governorate, Western of Nile Delta, Egypt between Longitudes $30^{\circ} 00^{\prime}$ and $30^{\circ} 33^{\prime} \mathrm{E}$ and Latitude $30^{\circ} 20^{\prime}$ and $30^{\circ} 30^{\prime} \mathrm{N}$. It parallels to (Cairo-Alex. Desert Highway) Km 90 to $\mathrm{Km} 110$. The study area covers about $2016 \mathrm{Km}^{2}$ (Figure 1).

The study area comprises a total area of about $770 \mathrm{~km}^{2}$. From the hydrological cross section, which pass through Wadi El Natrun area in West-East direction. Pliocene aquifer and from electrical sounding, this aquifer unit is mainly formed of alternating sand and clay and occasionally capped by thin layer of limestone. The Pliocene aquifer is considered as multi-layers' aquifer under confined to semiconfined condition. Most of these waters bearing layers belongs to the Upper and Middle Pliocene. In this study, the information of 111 pumping well and 14 observation well were collected as well as other parameters such as hydraulic conductivity. Table 1 shows the values of hydraulic conductivity, transmissivity, and storativity of Pliocene at Wadi El Natrun area of different authors. According to the analysis of Pliocene aquifer in the area of study, we can notice that, the hydraulic conductivity $(\mathrm{K})$ values ranged between $5 \mathrm{~m}$ /day at Wadi El Natrun area to $40 \mathrm{~m} /$ day in the east of Wadi El Natrun. The transmissivity (T) values ranged between $500 \mathrm{~m}^{2} /$ day to $1600 \mathrm{~m}^{2} /$ day in different zones of the Depression.

\section{Geologic setting}

The study area is occupied sedimentary rocks belonging to the Tertiary and Quaternary Eras. The sedimentary succession comprises several water-bearing formations, which are particularly influenced by structural features and thus affect the groundwater occurrences. However, the surface deposits dominating the area are studied through the geological map which shown in Figure 2. In the study area, Late Tertiary and Quaternary succession were studied by many authors. The subsurface geology of the study area is studied from the well logs as from the Wadi El Natrun deep well. The Pliocene aquifer is local in extent, covers the entire Wadi El Natrun area, and is discontinuously covered by Quaternary deposits of the Pleistocene Aquifer. As a result, the Pliocene aquifer is considered to be partially confined [20]. The Pliocene Aquifer's thickness ranges from 150 to $300 \mathrm{~m}$ thick [20].

\section{Hydrologic setting}

Hydrogeologic setting in the Wadi El Natrun area is complex, and there is still significant uncertainty as to the precise flow regime and hydraulic connections between the aquifers. Nonetheless, multiple studies have observed both local and regional groundwater flow to be concentrated toward the base of the valley where it discharges to eleven saline lakes [20].

\section{Govering equation}

A general form of the governing equation, which describes the three dimensional movement of groundwater flow of constant density through the porous media is [21]:

$$
\frac{\partial}{\partial x}\left[K x \frac{\partial h}{\partial x}\right]+\frac{\partial}{\partial y}\left[K y \frac{\partial h}{\partial y}\right]+\frac{\partial}{\partial z}\left[K z \frac{\partial h}{\partial z}\right]-w=S s \frac{\partial h}{\partial t}
$$

Where: $\mathrm{Kx}, \mathrm{Ky}, \mathrm{Kz}$ are values of hydraulic conductivity along the $\mathrm{x}$, $y$ and $z$ coordinate axes $(L / t)$; h: is the potentiometric head $(L)$; $w$ : is the volumetric flux per unit volume and represents sources and/or sinks of water per unit time $\left(\mathrm{t}^{-1}\right)$; Ss: is the specific storage of the porous material $\left(\mathrm{L}^{-1}\right)$; and $\mathrm{t}$ : is time $(\mathrm{t})$. The first part of this problem was run to get a steady state solution that takes the form:

$$
\frac{\partial}{\partial x}\left[K x \frac{\partial h}{\partial x}\right]+\frac{\partial}{\partial y}\left[K y \frac{\partial h}{\partial y}\right]+\frac{\partial}{\partial z}\left[K z \frac{\partial h}{\partial z}\right]-w=0.0
$$

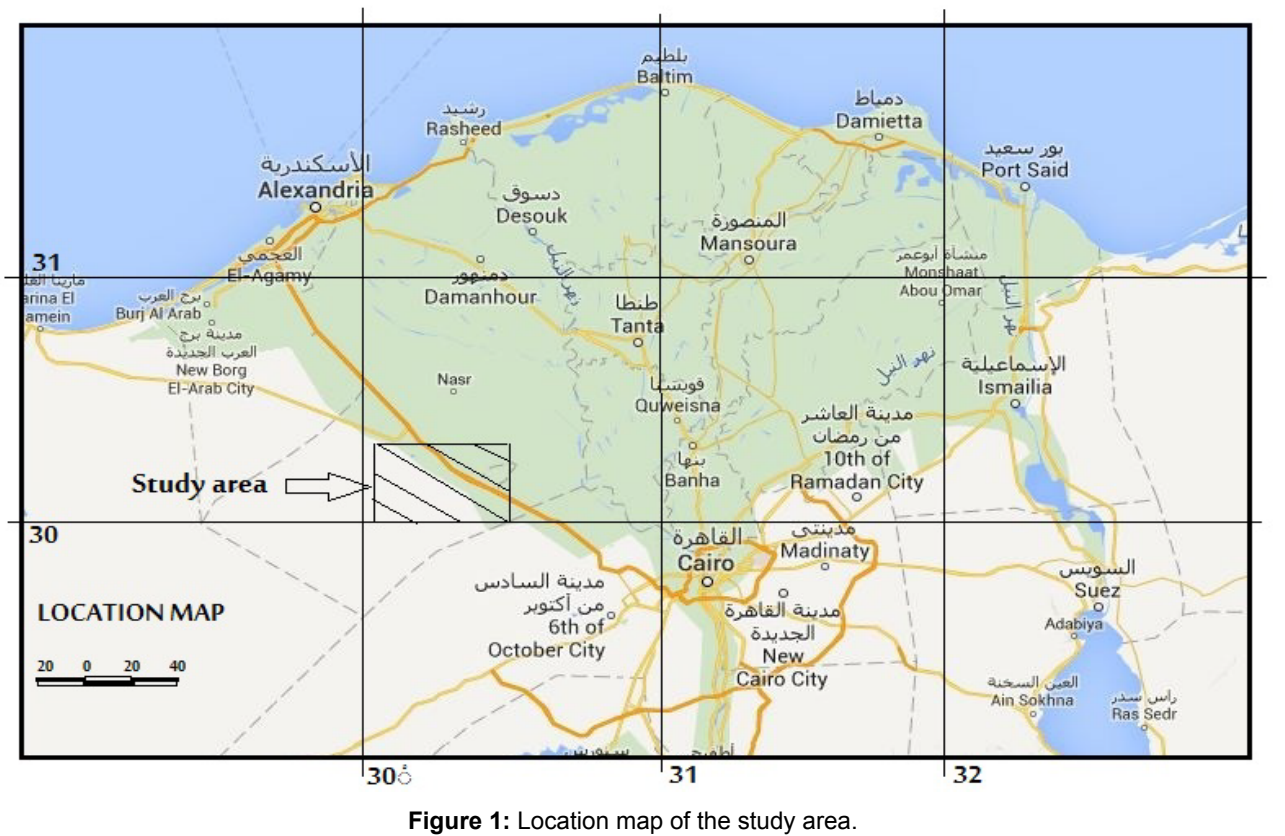




\begin{tabular}{|c|c|c|c|c|}
\hline \multirow{2}{*}{ Author } & \multirow{2}{*}{ Location of the test zone } & \multicolumn{4}{|c|}{ Hydraulic parameters } \\
\cline { 3 - 5 } & & $\mathbf{K}$ & $\mathbf{T}$ & $\mathbf{S}$ \\
\hline Ahmed [27] & North of Wadi El Natrun & - & 1043.9 & - \\
\hline Shata et al. [28] & Northeast Wadi El Natrun & 11 & - & - \\
\hline Desert research [28] & Northeast Wadi El Natrun & 31.9 & - & - \\
\hline General Petroleum [29] & East Wadi El Natrun & 26 & 2600 & $3.9^{\star} 10^{-3}$ \\
\hline Ahmed [27] & 2 km from El hamara lake & - & 794 & - \\
\hline Saad [30] & $\begin{array}{c}\text { East side of Wadi El } \\
\text { Natrun }\end{array}$ & 52.9 & 1291.7 & $3.95^{*} 10^{-3}$ \\
\hline RIGW [31] & Wadi El Natrun area & 9.8 & $500-327$ & $1.7^{*} 10^{-2}$ \\
\hline Mostafa [32] & East Wadi El Natrun & 47 & 943 & $7^{*} 10^{-4}$ \\
\hline Saad [30] & East Wadi El Natrun & 38.9 & 695.5 & $1.35^{\star} 10^{-3}$ \\
\hline Ahmed [27] & South Wadi El Natrun & - & 1660 & - \\
\hline El-Sheikh [33] & Beni Salama & 7.29 & 838 & $8.5^{*} 10^{-4}$ \\
\hline Sayed & $\begin{array}{c}\text { East Wadi El Natrun } \\
\text { (Jacob) }\end{array}$ & - & 3618 & 0.10466 \\
\hline El Sayed & $\begin{array}{c}\text { East Wadi El Natrun } \\
\text { (Recovery) }\end{array}$ & - & 2745 & - \\
\hline
\end{tabular}

Table 1: Hydraulic parameters of the Pliocene aquifer.

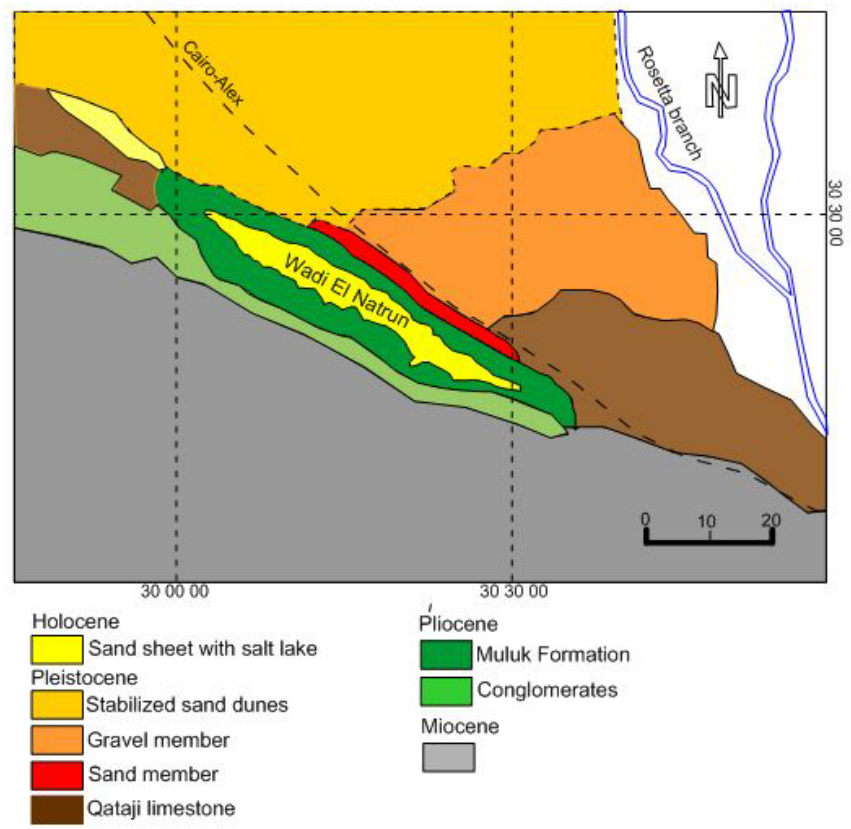

Figure 2: Geological map of Wadi El Natrun and its vicinities (Modified after Abu Zeid, 1984).

From the steady state solution, the hydraulic conductivity for model aquifers can be found. Then the equation is solved for transient case in order to solve for storage coefficient.

Karahan et al. identified transmissivity distribution of a twodimensional aquifer system under steady-state flow conditions. In that study, randomly selected Cartesian coordinates and error-free hydraulic heads are used as input and corresponding transmissivity values are used as output in the ANN model [18].

Shigidi et al. determined aquifer parameters by using ANN. In order to obtain observed hydraulic heads, they used MODFLOW with a stochastically generated transmissivity distribution [5]. Their network architecture uses the transmissivity values as input and the hydraulic heads as output. The error residuals between computed and observed hydraulic heads are reduced by adjusting the transmissivity field, and this process is cycled until the convergence is met. On the other hand, Garcia et al. [17] solved the same problem in their previous study- i.e., Shigidi et al., by adding a noise term to the observed hydraulic heads and they obtained more precise results than their previous study [5].

Choose the appropriate architecture of network among the available networks based on the type of the data and the problem. After many trials, Multilayer Perceptron network (MLP) has been chosen because of its high capabilities to generalize well in problems plagued with significant heterogeneity and nonlinearity. The Multilayer Perception (MLP) trained with the back-propagation algorithm is perhaps the most popular network for hydrologic modeling [22]. The majority of the ANN applications in water resources engineering involve the employment of a conventional Feed Forward Back Propagation Method (FFBP).

The important feature of this network is its ability to self-adapt the weights of neurons in intermediate layers to learn the relationship between a set of patterns given as examples and their corresponding outputs. So that after having been trained it can apply the same relationship to new input vectors and produce appropriate outputs from inputs that the system has never seen before, a feature known as the generalizability of an ANN [1]. The artificial neural network with a multilayer back propagation network has been used successfully in several studies [5,14,23-26].

\section{Conceptual model of Wadi el Natrun}

On the light of the hydrogeologic properties of the Pliocene aquifer in Wadi El Natrun Depression (chapter five), a pictorial representation (conceptual model) of the water flow system is constructed to this aquifer. The constructed conceptual model depends on the following facts:

1) The aquifer of Wadi El Natrun consists of five Geoelectric layers appear as follows:

- The first Geoelectric layer consist of dry sand, gravel and rock fragments, called the subsurface. The thickness of this layer is ranged between $(0.9 \mathrm{~m})$ and $(3.8 \mathrm{~m})$.

- The second Geoelectric layer is formed from shaly, sand and presence of shale interbedded with sand and differential amounts of water. The thickness of this layer is ranged between $(2.4 \mathrm{~m})$ and $(22 \mathrm{~m})$.

- The third geoelectric layer is made up of clayey, sand and gravel and underground water included in this layer, the thickness is ranged between $(61.6 \mathrm{~m})$ and $(69 \mathrm{~m})$.

- The fourth geoelectric layer is composed of clayey, sand and gravel, and considered the continuation of the third geoelectric layer. It includes the same lithology. These values give indication about the presence of underground water in this layer, as shown as shown the thickness of this layer is ranged between $(86.7 \mathrm{~m})$ and $(92.4 \mathrm{~m})$.

-The fifth geoelectric layer is barrier separating it and from the fourth geoelectric layer.

At the end, this section includes two water bearing layers, the third and the fourth geoelectric layers, that are saturated with water. These layers are considered the main aquifer of the study area.

2) The groundwater flow generally from NE to SW direction toward Wadi El Natrun Depression. The recharge from irrigation and the evapotranspiration will be neglected. The main discharge source is the present flowing productive well (48 wells). 
Citation: Khalaf S, Ahmed AO, Abdalla MG, El Masry AA (2017) Identification of Hydraulic Parameters of Wadi El Natrun Pliocene Aquifer Using Artificial Neural Network. Hydrol Current Res 8: 267. doi: 10.4172/2157-7587.1000267

Page 4 of 8

3) The Pliocene aquifer of Wadi El Natrun occurs under the confining conditions.

4) The base of the aquifer is not detected.

\section{Model application}

The model domain was selected to cover $770 \mathrm{~km}^{2}(55 \times 14 \mathrm{~km})$. The model domain was discretized using 144 row and 224 columns square cells. This discrimination produces 32,250 cells in the model layer. The width of the cells along rows (in $\mathrm{x}$-direction) is equal to the length along columns (in y-direction) $250 \mathrm{~m}$ as shown in Figure 3.

\section{Estimating of hydraulic head}

After finish the calibration of the MODFLOW model, and reached a good match between observed and calibrated head, as shown previous, the model will be ready to estimate the hydraulic distribution for all cells (Figure 4) which will use in the artificial neural network model. The values of hydraulic head in each cell as well as the coordinates of these cells can be exported as a .txt. File which will used later in the next chapter to predict the transmissivity and storativity using ANNs.

\section{Construction of ANN model}

Construction ANN model utilization FFBP Neural Networks (MLP) which built in MATLAB program version 7. Different ANN structure had been investigated to find optimum ANN model. The optimum neuron number in each hidden layer was also investigated.

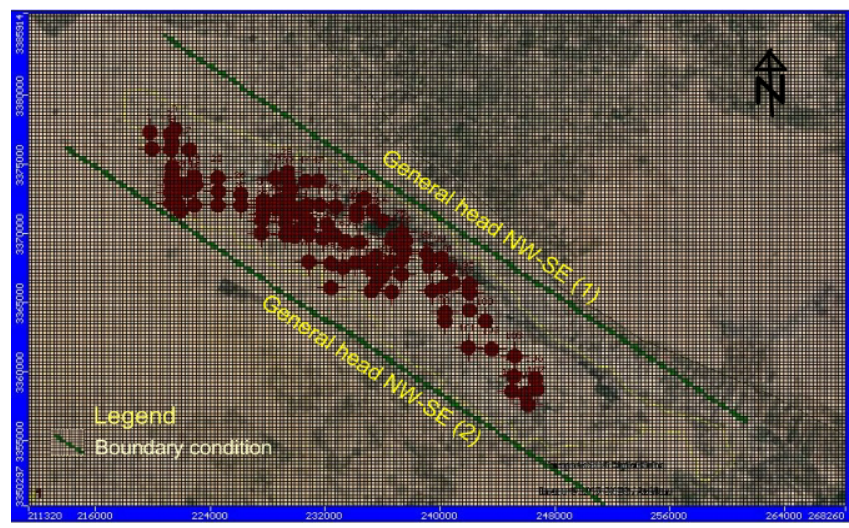

Figure 3: Flow model boundaries, grid, and pumping wells.

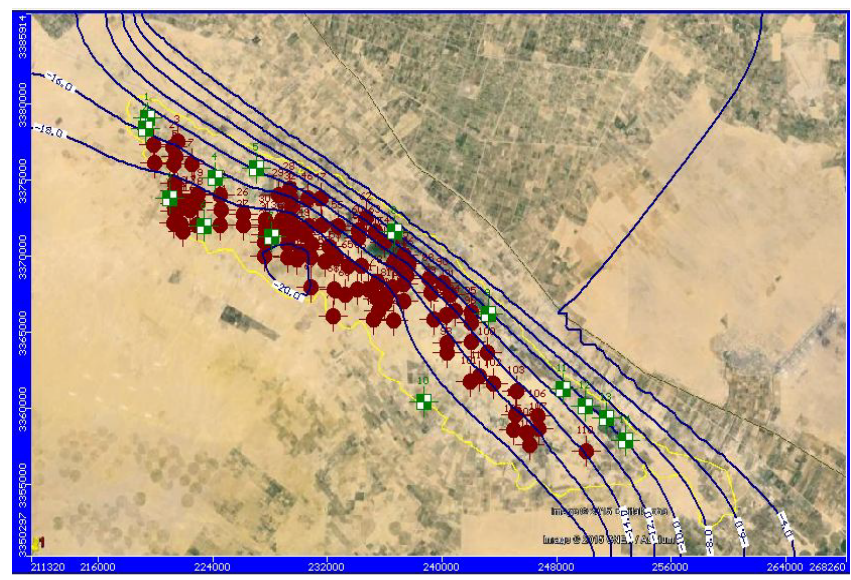

Figure 4: Head contour map of the model area.
In the ANN model architecture, the input layer includes 4 input (hydraulic head, Cartesian coordinates, and the time of observation), and the output layer include 2 outputs (transmissivity and storativity). In order to find the best number of hidden layers of ANN model many networks with different structure have been developed. These models had two hidden layers. The number of neuron in each hidden layer is also very important in the structure of ANN. The low number of neurons in each layer decreases the learning performance. In contrast, a high number of neurons increase the training time. Therefore, the optimum number of neurons in each layer is essential to build the ANN structure. In the present research, a different number of neurons (10-17) have been tested to find the best ANN structure. By comparing performance of developed ANN models the optimum number of neurons in each hidden layer for different structure $(3 \times 6 \times 2),(3 \times$ $10 \times 2),(3 \times 6 \times 4 \times 2),(3 \times 8 \times 4 \times 2),(3 \times 10 \times 4 \times 2),(3 \times 12 \times 6 \times$ $2),(3 \times 14 \times 6 \times 2),(3 \times 14 \times 8 \times 2),(3 \times 16 \times 8 \times 2)$ and $(3 \times 17 \times 8 \times$ 2). They had the same input and output layer, so they just differ with the hidden layers. The best results obtained from the network with two hidden layers with 17 and 8 hidden neurons, respectively.

For present study, FFBP $(3 \times 17 \times 8 \times 2)$ architecture is selected in the model. The logsig transfer function is applied in the first hidden layer and the purelin transfer function is applied in the second hidden layer (Figure 5).

\section{Construction data matrix of ANN model}

The matrixes of ANNs are different as compare with other matrixes, because that every parameter value should be arranged at one a row of this matrix. There are three matrixes need to be constructed in older to use in artificial neural networks model. Two matrixes for training the ANNs model, while the third matrix used as input parameters that we want to get its output (Table 2).

\section{Network training, validation, and testing}

Generally, the default setting of artificial neural network divided date into three divisions, which are training, validation and testing with a proportion of $60 \%, 20 \%$ and $20 \%$ of data respectively. The training set the large proportion of data to learn pattern present in the data.

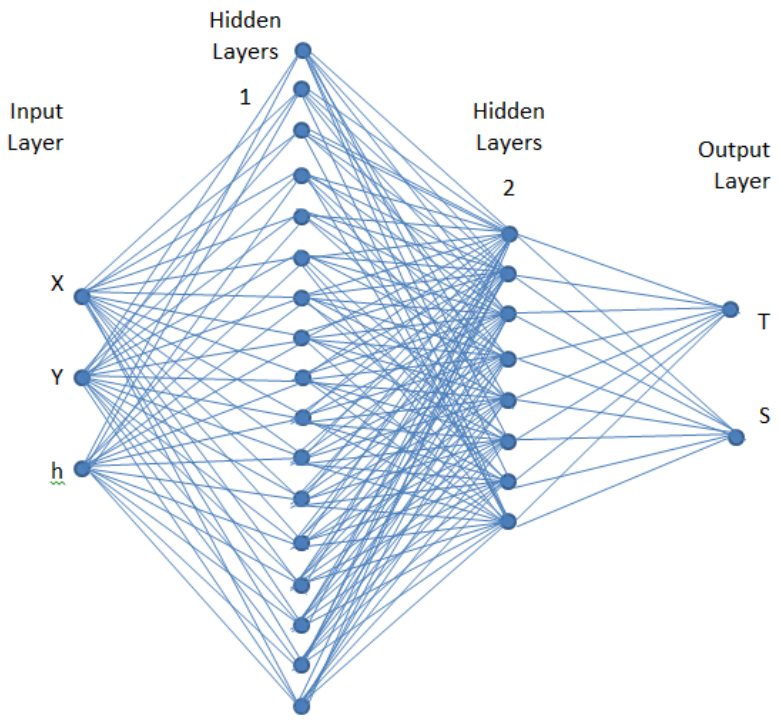

Figure 5: Numbers of neuron of each layer 


\begin{tabular}{|c|c|c|c|c|c|}
\hline $\mathbf{N}$ & $\mathbf{X}$ & $\mathbf{Y}$ & $\mathbf{h}$ & $\mathbf{T}$ & $\mathbf{S}$ \\
\hline 1 & 219921.6 & 3378928 & -10 & 1100 & 0.000155 \\
\hline 2 & 219735.4 & 3378244 & -11 & 731 & 0.0000554 \\
\hline 3 & 221375.6 & 3373596 & -18.25 & 955 & 0.0000152 \\
\hline 4 & 224584.5 & 3374936 & -12.5 & 1366 & 0.00288 \\
\hline 5 & 227479.5 & 3375523 & -8.5 & 613 & 0.00265 \\
\hline 6 & 223747 & 3371761 & -18 & 840 & 0.00135 \\
\hline 7 & 228461.4 & 3370956 & -16.25 & 827 & 0.00183 \\
\hline 8 & 237002.8 & 3371180 & -6.5 & 1435 & 0.00177 \\
\hline 9 & 243511.9 & 3365666 & -7.25 & 650 & 0.017 \\
\hline 10 & 238908.6 & 3359950 & -17.75 & 719 & 0.0075 \\
\hline 11 & 248609.4 & 3360650 & -8 & 1460 & 0.00181 \\
\hline 12 & 250137.2 & 3359494 & -6.75 & 870 & 0.0017 \\
\hline 13 & 251607.1 & 3358735 & -6.85 & 718 & 0.0012 \\
\hline 14 & 252927.7 & 3357222 & -7.25 & 595 & 0.0095 \\
\hline 15 & 243511.9 & 3365666 & -8.1 & 920 & 0.10466 \\
\hline 16 & 238908.6 & 3359950 & -13 & 1235 & 0.0166 \\
\hline 17 & 248609.4 & 3360650 & -7.5 & 630 & 0.0845 \\
\hline 18 & 243887.9 & 3361092 & -16 & 575 & 0.0124 \\
\hline 19 & 247490.7 & 3356758 & -16.5 & 535 & 0.0099 \\
\hline 20 & 249098.6 & 3356194 & -13.5 & 719 & 0.0075 \\
\hline & & Table 2: Data for training ANN. & \\
\hline & & & & \\
\hline
\end{tabular}

The conditions to stop training processes were set before the network is trained. Training was controlled by some of conditions as: the maximum number of iterations, target performance which specifies the tolerance between the neural network prediction and actual output, the maximum run time and the minimum allowed gradient and. The overall training of the ANN will involve the following processes; the input values of the first layer are weighted and passed on to the hidden layer; the neurons in the hidden layer will produce outputs by applying an activation function to the sum of the weighted input values; the resulting outputs are then weighted by the connections between the hidden and output layer.

The network technique enable the user to make good training by shows the result with network calculated by submitted a figure shows the training fitting. Figure 6 shows good fitting which mean that the network gives a result data closed to the data that we had insert as output. The training coefficient $\mathrm{R}$ represent the fitting of observed invers calculated which is 0.98296 , and this number is very closed to 1 , so that mean we had good match.

Validation is the simple check of the model which used $20 \%$ of data to ensure that the training is able to give accepted result and good match between observed and calculated data model is controlled using the same synaptic weights in the validation part. For validation $\mathrm{R}=0.898$ consider well because that, there is a good fitting between both observed and validate data (Figure 7).

Testing is an important process, which consider as the final check of the network to check the ability of this network to predict and gives accurate. Then we can decide that the model is good and show good match between observed and calculated data. Figure 8 is a simple chart shows the coefficient (R) and the result of the fitting between validate data and the calculated data (Table 3 ).

Performance: The performance of the ANN model can be quantified by statistical measure addressing the magnitude of the variable. The model can be validated in terms of root mean square error (RMSE), correlation coefficient (R) and scatter index (SI) as follows

$$
\begin{aligned}
& R M S E=\sqrt{\frac{\sum_{i=1}^{N}\left(y_{i}-x_{i}\right)^{2}}{N}} \\
& R=\frac{\sum_{i=1}^{N}\left(x_{i}-x^{-}\right)-\left(y_{i}-y^{-}\right)}{\sqrt{\sum_{i=1}^{N}\left(x_{i}-x^{-}\right)^{2} \sum_{i=1}^{N}\left(y_{i}-y^{-}\right)^{2}}} \\
& S I=\frac{R M S E}{x^{-}}
\end{aligned}
$$

Where $\mathrm{x}_{\mathrm{i}}$ is the observed values at the $\mathrm{i}^{\text {th }}$ time step, $\mathrm{y}_{\mathrm{i}}$ is the simulated values, $\mathrm{N}$ is the number of time increment and $\mathrm{x}^{-}$and $\mathrm{y}$ are the mean values of observation and simulation, respectively.

The desired results are generated in the output layer. The network achieves the desired learning by adjusting its interconnected weights continuously until there is a close match between the outputs from the neurons and the output from the training data. The difference between the predicted outputs and the original outputs is referred to as error. Figure 9 shows the fitting and the coefficient for all training, validation, and testing.

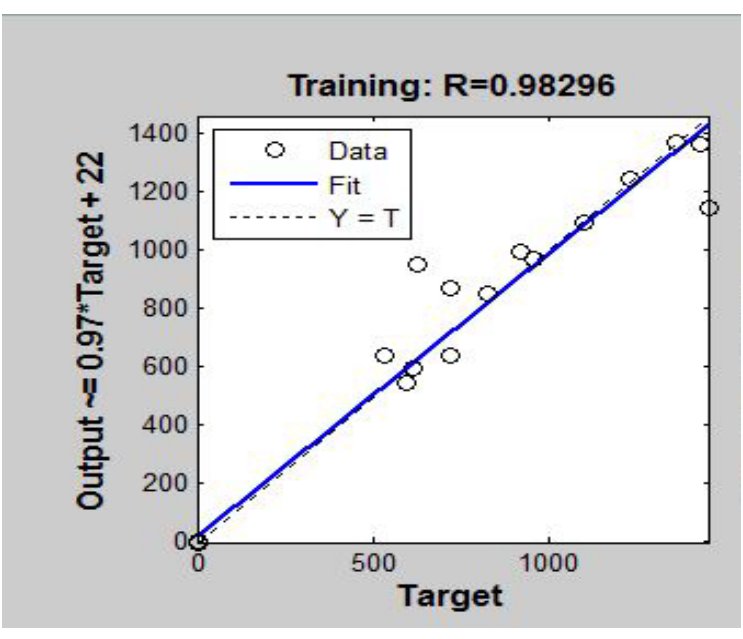

Figure 6: Training chart.

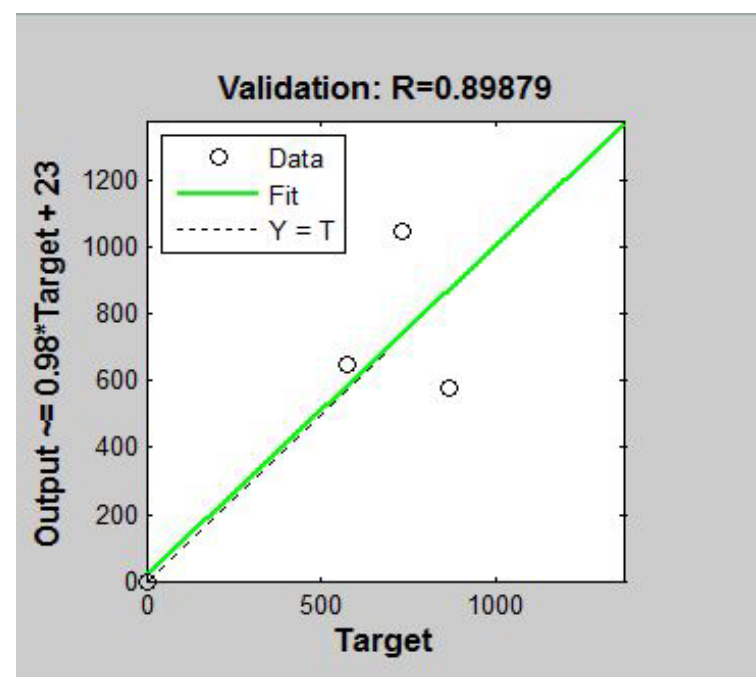

Figure 7: Validation chart. 


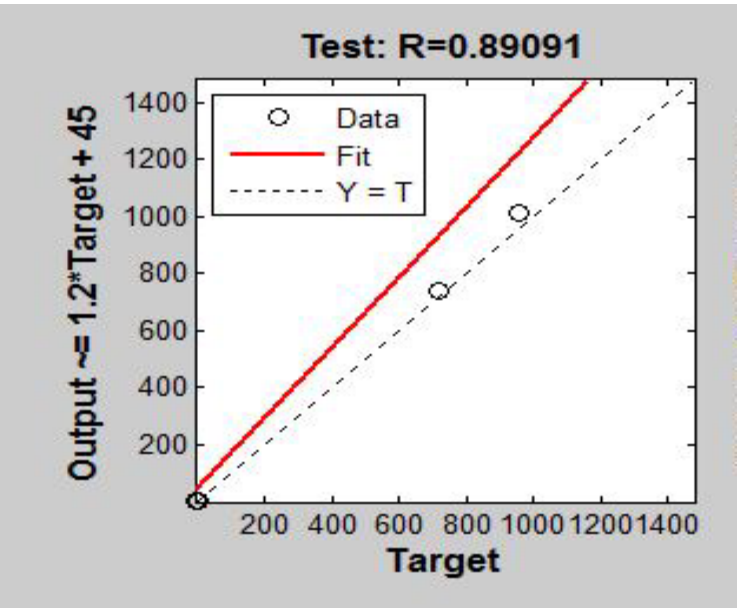

Figure 8: Chart shows the validation coefficient (R).

\begin{tabular}{|c|c|c|c|}
\hline \multirow{2}{*}{ Models No. } & \multicolumn{3}{|c|}{ No. of coefficient } \\
\cline { 2 - 4 } & Training & Validation & Testing \\
\hline 1 & 0.6361 & 0.64 & 0.5443 \\
\hline 2 & 0.7135 & 0.5443 & 0.6577 \\
\hline 3 & 0.7974 & 0.6577 & 0.7411 \\
\hline 4 & 0.8773 & 0.7411 & 0.7974 \\
\hline 5 & 0.8812 & 0.7562 & 0.7934 \\
\hline 6 & 0.91545 & 0.837 & 0.8253 \\
\hline 7 & 0.9154 & 0.8423 & 0.8517 \\
\hline 8 & 0.9626 & 0.8674 & 0.8742 \\
\hline 9 & 0.9795 & 0.8734 & 0.8734 \\
\hline 10 & 0.9995 & 0.87824 & 0.89091 \\
\hline
\end{tabular}

Table 3: Coefficient of training, validation and testing of ANN models.

Sensitivity analysis: Input variables are not, in general, independent- that is, there are interdependencies between variables. Sensitivity analysis rates variables according to the deterioration in modeling performance that occurs if that variable is no longer available to the model. In so doing, it assigns a single rating value to each variable. However, the interdependence between variables means that no scheme of single ratings per variable can ever reflect the subtlety of the true situation. Consider, for example, the case where two input variables encode the same information (they might even be copies of the same variable). A particular model might depend wholly on one, wholly on the other, or on some arbitrary combination of them. Then sensitivity analysis produces an arbitrary relative sensitivity to them. Moreover, if either is eliminated the model may compensate adequately because the other still provides the key information. It may therefore rate the variables as of low sensitivity, even though they might encode key information. Similarly, a variable that encodes relatively unimportant information, but is the only variable to do so, may have higher sensitivity than any number of variables that mutually encode more important information.

\section{Discussion}

From the previous section, it is shown that the proposed ANN model may be used to identify the transmissivity and storativity distributions of an aquifer in an inverse modeling framework. For real-world problems, there are some important issues that require further analysis. Note that the same input structure, network architecture, and solution parameters are used in this section. The contours of predicted vs. actual transmissivities and storativities for noise data conditions can be seen in Figures 10 and 11, respectively. It is clearly seen from Figures 10 and 11 that the increase in the standard deviations may not significantly change the prediction performance of the proposed ANN model. This situation states that the proposed ANN model may have generalization ability. Therefore, it may be used in the real-world parameter estimation problems.

\section{Results of Ann Model}

After finish, the training by obtained good match between observed and predicted data with good validation and testing fitting then I saved the network in order to use it in prediction. The saving part of network mean saving of all weights that the network reached for obtaining good results. Then we use the same network to predict the distribution of both transmissivity and storativity. For that, we imported the new matrix of input, which include the distribution of head, which represented by the head $(\mathrm{h})$ and the coordinates ( $\mathrm{x}$ and y) which obtained from the MODFLOW model. By run the model to simulate the new data. The result appears directly in anew matrix include predicted transmissivity and storativity. Figures 12 and 13 shows the distribution of transmissivity and storativity respectively.

As shown before the actual values of transmissivity ranged between

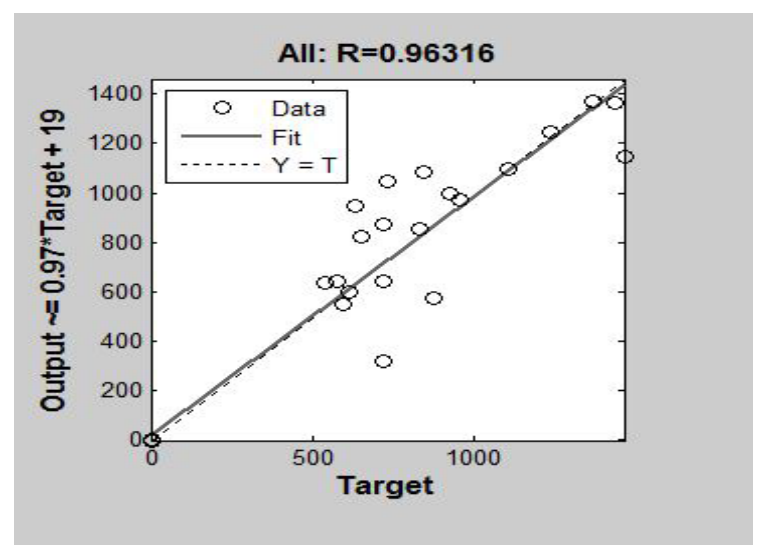

Figure 9: Fitting and the coefficient for training, validation, and testing.

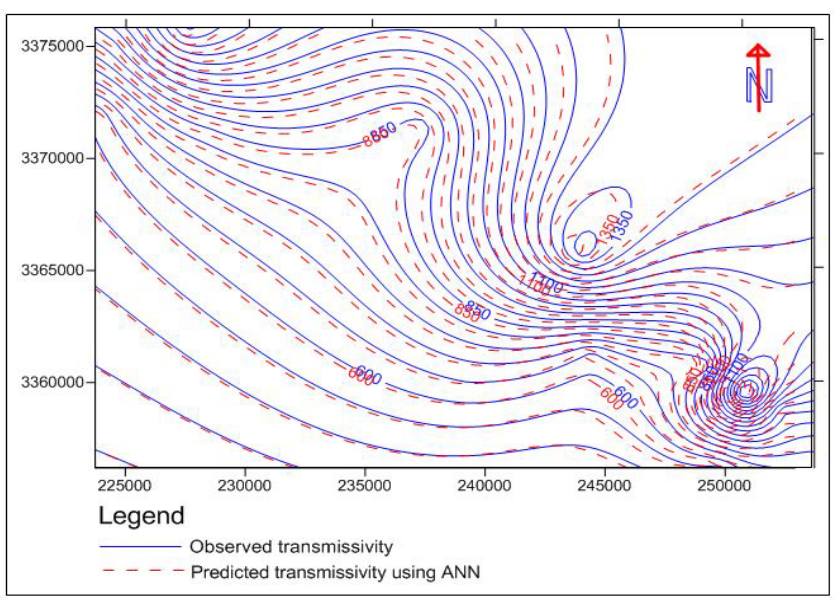

Figure 10: Actual and predicted distribution of transmissivity. 
Citation: Khalaf S, Ahmed AO, Abdalla MG, El Masry AA (2017) Identification of Hydraulic Parameters of Wadi El Natrun Pliocene Aquifer Using Artificial Neural Network. Hydrol Current Res 8: 267. doi: 10.4172/2157-7587.1000267

Page 7 of 8

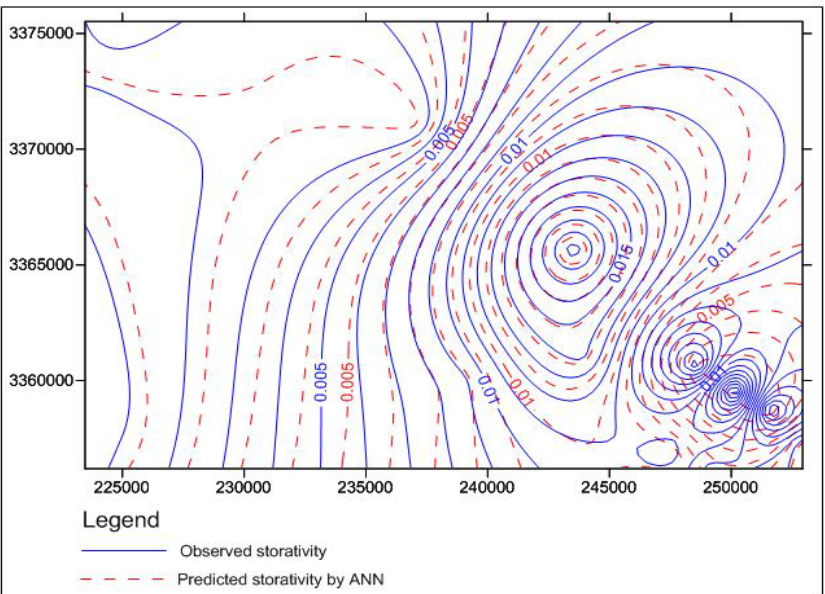

Figure 11: Actual and predicted distribution of storativity.

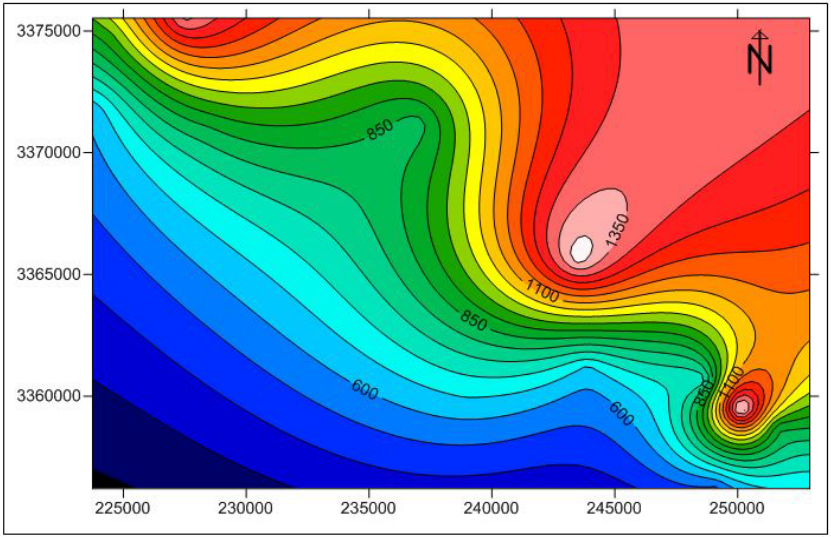

Figure 12: Distribution of predicted transmissivity using ANN

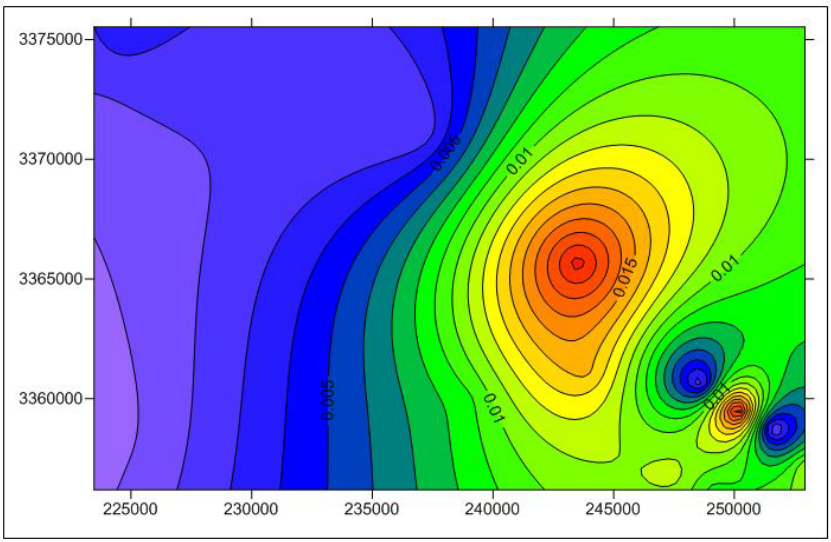

Figure 13: Distribution of predicted storativity using ANN.

500 and $1600 \mathrm{~m}^{2} /$ day (Figure 10) and the actual values of storativity randed between 0.001 to 0.05 . The values of predicted transmissivity are in the same range of the actual, also the distribution of the predicted transmisivity is closed to the actual one (Figure 14). Also, the values of predicted storativity are in the same range of the actual, also the distribution of the predicted storativity is closed to the actual one (Figure 11).

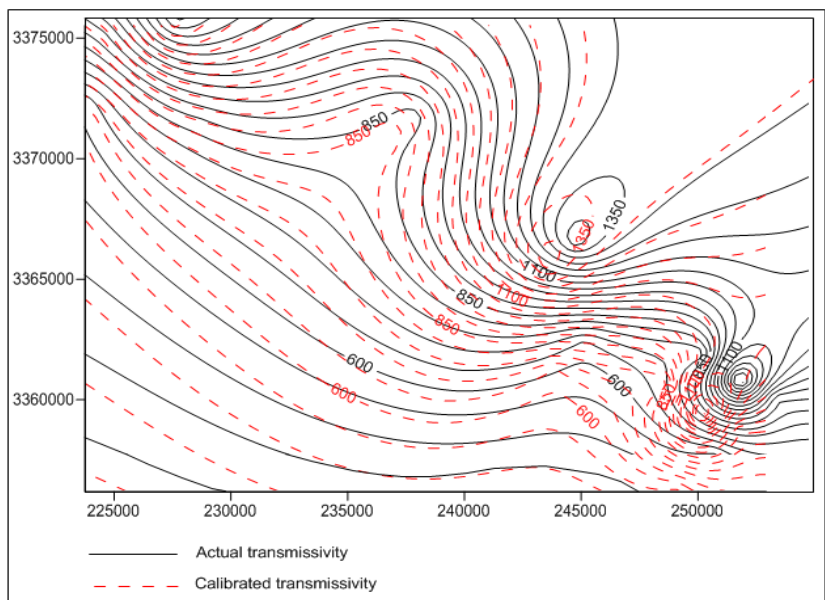

Figure 14: Actual and calibrated transmissivity.

\section{Conclusion}

An ANN solution technique is proposed to simultaneously identify the transmissivity and storativity distributions of an aquifer system. A hypothetical aquifer is modeled on MODFLOW for transient flow conditions, and its results are used as observed values to train and validate the developed ANN model. The proposed ANN model requires Cartesian coordinates, sampled piezometric heads, and sampling times as input and associated transmissivities and storativities as output. The number of hidden layer neurons is determined using try and error. The synaptic weights of the ANN model are defaults. To prevent potential over-training problems, the available data set is divided into three parts (training, validation, and testing) and overtraining in the model is controlled using the same synaptic weights in the validation part. After obtaining the synaptic weights, transmissivity and storativity distributions are predicted head values for different simulation times. Results showed that predicted transmissivity and storativity distributions are very close to actual values. In addition, the performance of the ANN model is tested for noise data conditions in the observed head values. For this purpose, the available observed piezometric heads are corrupted with Gaussian noise of zero mean and different standard deviations. Results showed that there is no significant change in the prediction performance of the proposed ANN model and this model may be applied to real aquifer parameter estimation problems.

\section{References}

1. Mehrotra P, Quaicoe JE, Venkatesan R (1997) Induction motor speed estimation using artificial neural networks. Canadian Conference on Electrical and Computer Engineering

2. Aziz ARA, Wong KV (1992) A neural network approach to the determination of aquifer parameters. Ground Water 30: 164-166.

3. Zio E (1997) Approaching the inverse problem of parameter estimation in groundwater models by means of artificial neural network. Prog Nuclear Energy 31: $303-315$

4. Balkhair KS (2002) Aquifer Parameters Determination for Large Diameter Wells Using Neural Network Approach. J Hydrology 265: 118-128.

5. Shigdi A, Gracia LA (2003) Parameter estimation in ground-water hydrology using artificial neural networks. J Comput Civil Eng 17: 281-289.

6. Karahan H, Ayvaz MT (2004) Forecasting Parameters Using Artificial Neura Networks. J Porous Media 5: 43-49.

7. Li S, Liu Y (2005) Parameter Identification procedure in Groundwater Hydrology with Artificial Neural Networks ICIC 2005, Part II, LNCS 3645, 276-285. 
Citation: Khalaf S, Ahmed AO, Abdalla MG, El Masry AA (2017) Identification of Hydraulic Parameters of Wadi El Natrun Pliocene Aquifer Using Artificial Neural Network. Hydrol Current Res 8: 267. doi: 10.4172/2157-7587.1000267

Page 8 of 8

8. Morshed J, Kaluarachchi JJ (1998) Parameter estimation using artificial neural Network and genetic algorithm for free-product migration and recovery. Water Resour Res 34: 1101-1113

9. Lin GF, Chen GR (2006) An improved Neural Network approach to the determination of aquifer parameters. J of Hydrology 316: 281-289.

10. Lohani AK, Krishan G (2015) Application of artificial neural network for groundwater level simulation in Amritsar and Gurdaspur districts of Punjab, India. J Earth Sci Climate Change 6: 274.

11. Lohani AK, Krishan G (2015) Groundwater level simulation using artificia neural network in southeast, Punjab, India. J Geology Geophy 4: 206.

12. Harrouni K, Ouazar D, Wrobel LC, Cheng AHD (1997) Groundwater parameter estimation by optimization and DRBEM. Eng Anal Boun Elem 19: 97-103.

13. Maier HR, Dandy GC (1998) The Effect of Internal Parameters and Geometry on the Performance of Back-Propagation Neural Networks: An Empirical Study. Environmental Modeling \& Software 13: 193-209.

14. Coppola E, Szidarovszky F, Poulton M, Charles E (2003) Artificial neura network approach for predicting transient water levels in a multilayered groundwater system under variable state, pumping, and climate conditions. J Hydrol Eng 8: 348-360.

15. Daliakopoulos IN, Coulibaly P, Tsanis IK (2005) Groundwater level forecasting using artificial neural networks. J Hydrol 309: 229-240.

16. Lingireddy S (1998) Aquifer Parameter Estimation using genetic Algorithms and Neural networks. Civil Engrg Env Syst 15: 125-144.

17. Garcia LA, Shigidi A (2006) Using neural networks for parameter estimation in ground water. J Hydrol 318: 215-231.

18. Karahan H, Ayvaz MT (2006) Forecasting aquifer parameters using artificial neural networks. J Porous Media 9: 429-444.

19. Maier HR, Dandy GC (2000) Neural Networks for the Prediction and Forecasting of Water Resources Variables: A Review of Modeling Issues and Applications. Environmental Modeling \& Software 15: 101-124

20. Masoud AA, Atwia MG (2011) Spatio-temporal Characterization of the Pliocene Aquifer Conditions in Wadi El-Natrun Area, Egypt. Environmental Earth Sciences 62: 1361-1374.
21. Freeze RA, Cherry JA (1979) Groundwater: Englewood Cliffs, NJ, PrenticeHall, p: 604

22. ASCE Task Committee: on Application of Artificial Neural Networks in Hydrology I: Preliminary Concepts. J of Hydrologic Eng 5: 115-123.

23. Coppola EA, Rana AJ, Poulton MM, Szidarovszky F, Uhl VW (2005) A Neura Network Model for Predicting Aquifer Water Level Elevations. Ground Water 43: 231-241.

24. Nayak PC, Rao YRS, Sudheer KP (2006) Groundwater Level Forecasting in a shallow Aquifer Using Artificial Neural Network. Water Resour Manage 20: 77-90.

25. Karahan H, Ayvaz MT (2005) Groundwater parameter estimation by optimization and dual reciprocity finite differences method. J Porous Media 8: 211-223.

26. Karahan H, Ayvaz MT (2008) Simultaneous parameter identification of a heterogeneous aquifer system using artificial neural networks. Hydrogel $\mathrm{J} 16$ : 817-827.

27. Ahmed SA (1999) Hydrogeological and isotope assessment of groundwater in Wadi El-Natrun and Sadat City, Ain Shams University, Cairo, Egypt, p: 237.

28. Shata AA, El-Fayoumy IF (1970) Geomorphology, geology, and, the hydrogeology soil of Wadi El-Natrun- Maryut Agriculture Project Sympos. Hydrology of Nile Delta, UNISISCO 2: 385-396.

29. General Petroleum Company (GPC) (1977) Progress Report on geology and Stratigraphy of western Desert, Cairo, Egypt, p: 88.

30. Saad KF (1962) Groundwater hydrology, in preliminary report on the geology, hydrogeology, and groundwater hydrology of Wadi El-Natrun and adjacent area, Part 3, Cairo, U.A.R., Desert Institute, The General Desert Development Organization, p: 61.

31. RIGW/IWACO (1990) Hydrogeological inventory and development plan of groundwater Western Nile Delta region, Report, TN 77.01300-90-02.

32. Mostafa NE (1993) Hydrogeological and Hydro studies on Wadi El-Farigh Area, Western Desert, Egypt. M.Sc. Thesis, Faculty of Science, El-Minufiya University Shibin El-Kom, Egypt, p: 132.

33. El-Sheikh (2000) Hydrogeology of the area north and west of Wadi El-Natrun. M. Sc. Thesis Faculty of Science, Minufiya Univ, Egypt, p: 151. 